\title{
$\mathrm{BER}$ 성능 향상을 위해 제안하는 새로운 $\mathrm{CDSK}$ 수신기
}

\author{
이 준 현, 유 흥 균
}

\section{A Novel Design of CDSK Receiver for Improving the BER Performance}

\author{
Jun-Hyun Lee’, Heung-Gyoon Ryu \\ 요 약
}

카오스 방정식의 초기 조건이 미세하게 변하면 전혀 다른 신호가 생성되기 때문에 카오스 통신은 초기 조건에 민감한 특징을 갖는다. 또한, 카오스 통신 시스템은 비주기성, 광대역성, 신호의 비예측성, 구현의 용이성 등의 특 성을 가지고 있다. 이런 특징으로 인해 카오스 통신 시스템은 다른 시스템에 비해 보안성이 우수하게 평가된다. 하 지만 기존 카오스 통신 시스템의 송신기와 수신기는 간섭 신호나 잡음에 영향을 많이 받기 때문에 BER 성능은 다른 디지털 시스템보다 나쁘게 평가된다. 그래서 카오스 통신 시스템의 BER 성능을 향상시키기 위한 연구가 지 속적으로 이루어지고 있다. 본 논문에서는 BER 성능 향상을 위한 새로운 CDSK 수신기를 제안한다. 기존 CDSK 수신기와 제안한 $\mathrm{CDSK}$ 수신기의 BER 성능 비교와 제안한 $\mathrm{CDSK}$ 수신기의 $\mathrm{BER}$ 성능 향상을 평가한다. 또한, 새로운 CDSK 수신기를 사용할 때, 확산인자에 따른 BER 성능을 평가하여 최적의 확산인자를 찾는다. 새로운 $\mathrm{CDSK}$ 수신기를 사용하면 기존 $\mathrm{CDSK}$ 수신기보다 BER 성능이 향상되며 간섭 신호나 잡음의 영향을 거의 받지 않기 때문에 확산인자 값이 커질수록 BER 성능은 향상된다.

Key Words : CDSK, CDSK Receiver, BER performance improvement, Spreading Factor, Chaos Receiver.

\section{ABSTRACT}

Chaos communication system has a sensitive characteristic to initial conditions, because completely another signal is generated when initial condition of chaos equation is changed subtly. Also, chaos communication systems have the characteristics of non-periodic, non-predictability, the broadband signal, such as ease of implementation. Due to these characteristics, security of chaos communication system generally is evaluated better than other systems. However, BER(Bit Error Rate) performance is evaluated worse than other digital system, because existing chaos communication system's transmitter and receiver are strong influence by interference signal and noise. So, research to improve the BER performance of the chaotic communication system is performed continuously. In this paper, We will propose a new CDSK(Correlation Delay Shift Keying) receiver for BER performance improvement. After we compare to the performance of existing CDSK receiver and proposed CDSK receiver, BER performance of proposed CDSK receiver evaluate. Also, when using the new CDSK receiver, we evaluate the BER performance according to the spreading factors and find an optimum spreading factor. If chaos communication system use a new CDSK receiver, BER performance is improved than existing CDSK receiver. Also, if spreading factor's value is increased, BER performance is improved, because it is not nearly affected by interference signal and noise.

※ 본 논문은 2012년도 정부(교육과학기술부)의 재원으로 한국연구재단의 지원을 받아 수행된 기초연구사업임(No. 2012017339).

- 주저자 : 충북대학교 전자공학과, toogee89@nate.com, 학생회원

- 교신저자 : 충북대학교 전자공학과, ecomm@cbu.ac.kr 정회원

논문번호 : KICS2013-06-260, 접수일자 : 2013년 6월 19일, 최종논문접수일자 : 2013년 7월 31일 


\section{I. 서 론}

기존의 디지털 통신 기술은 성능을 향상시키기 위해 선형 시스템을 사용하였다. 하지만 성능의 향상을 위해 선형 시스템을 사용함에 있어서 기본적인 한계에 부딪 치게 되어 비선형 통신 시스템을 연구하기 시작하였다. 카오스 통신 시스템은 비주기성, 광대역성, 신호의 비 예측성, 구현의 용이성 등의 특성을 가지고 있다. 그리 고 카오스 신호는 무작위로 생성되는 신호로써 원리적 으로는 예측이 가능하며 미래의 값은 과거의 값으로 구할 수 있다. 이로 인해 초기조건을 정확히 모른다면 미래의 값을 예측할 수 없으며 이로 인해 카오스 통신 시스템은 초기조건에 민감한 특징을 갖는다 ${ }^{[1,2]}$.

이러한 특징으로 인해 카오스 통신 시스템은 다른 시스템보다 높은 보안성을 가진다. 또한 신호가 카오스 신호에 의해 확산되어 전송되므로 다른 사용자의 신호 감지가 어렵고 전파 방해에 강하다는 특징을 갖는다. 또한 도청 확률을 줄일 수 있기 때문에 보안성이 높게 평가되는 것이다 ${ }^{[3,4]}$. 하지만 카오스 통신 시스템은 다 른 디지털 시스템보다 BER 성능이 나쁘다는 단점을 가진다 ${ }^{[4]}$. 카오스 통신 시스템은 BER 성능이 나쁜 특 성을 가지고 있기 때문에 카오스 사용자들은 BER 성 능을 향상시키기 위한 연구를 지속적으로 수행하고 있 다. 기존 연구를 보면, 카오스 맵에 따른 BER 성능을 평가하여 가장 좋은 $\mathrm{BER}$ 성능을 보이는 카오스 맵을 찾는다 ${ }^{[5]}$. 또, 카오스 변조 방식에 따른 BER 성능을 평가하거남] 카오스 맵의 확률밀도함수를 분석하여 최고의 BER 성능을 갖는 새로운 카오스 맵을 제안하 는 연구가 있다.

하지만 가장 좋은 $\mathrm{BER}$ 성능을 갖는 카오스 맵이나 변조 방식을 찾는 기존 연구에서 $\mathrm{BER}$ 성능 향상에는 한계가 존재한다. 따라서 $\mathrm{BER}$ 성능을 근본적으로 향 상시킬 수 있는 연구가 필요하다. 기존의 수신기 구조 는 원하는 신호 외에 잡음과 같이 더해지는 요소가 굉 장히 많다. 그렇기 때문에 카오스 통신 시스템의 BER 성능이 나쁘게 평가되는 것이다. 따라서 본 논문에서는 새로운 CDSK(Correlation Delay Shift Keying) 수신 기 구조를 제안한다. 기존 연구에서는 원하는 신호 외 에 잡음과 같이 더해지는 요인에 가장 적게 영향을 받 는 카오스 맵이나 변조 방식을 찾았지만 제안하는 수 신기 구조는 BER 성능을 나쁘게 하는 근본적인 원인 을 줄임으로써 $\mathrm{BER}$ 성능을 향상시킨다. 따라서 제안 하는 수신기는 디지털 통신 시스템의 BER 성능과 비 슷한 수준까지 BER 성능을 향상시킬 수 있다.

\section{Correlation Delay Shift Keying System}

기존 DCSK(Differential Chaos Shift Keying) 변조 방식에서는 송신기에 스위치가 존재하여 두 번 전송이 이루어져 전력 낭비와 도청의 문제점이 발생한다미. 이 러한 문제점으로 인해 제안된 기법이 CDSK 방식이다. CDSK 방식은 기존 DCSK 변조 방식의 송신기에 있 는 스위치를 가산기로 대체한 시스템이며, 송신된 신호 가 결코 반복되지 않는다는 특징을 가진다.

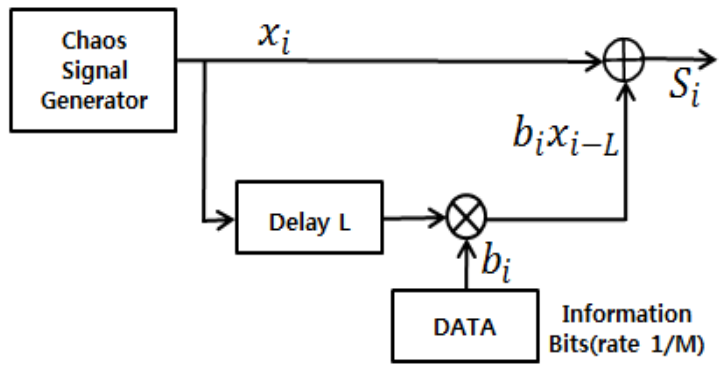

그림 1. 기존 CDSK 방식의 송신기.

Fig. 1. Existing CDSK Transmitter.

그림 1 은 $\mathrm{CDSK}$ 방식의 송신기를 나타낸 것이다. CDSK 방식의 송신신호는 카오스 신호 발생기에서 발 생시킨 카오스 신호와 정보신호가 곱해진 지연된 카오 스 신호의 합으로 나타낼 수 있다.

$$
S_{i}=x_{i}+b_{i} x_{i-L}
$$

식(1)은 송신기에서 출력되는 송신 신호 $\left(S_{i}\right)$ 를 나타 낸 것이다. 식(1)에서 정보신호 $b_{i}$ 는 1 과 0 이 아닌 1 과 -1 로 구성되어 있다.

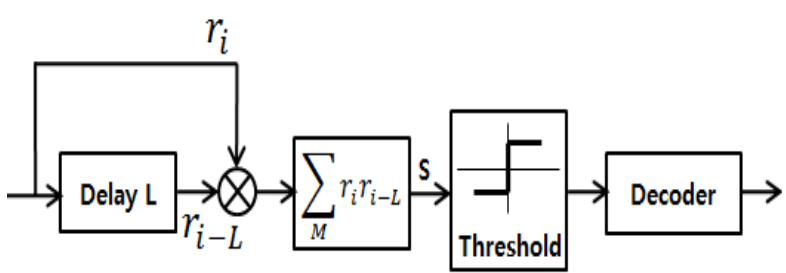

그림 2. 기존 CDSK 방식의 수신기.

Fig. 2. Existing CDSK Receiver.

그림 2는 CDSK 방식의 수신기를 나타낸 것이다. $\mathrm{CDSK}$ 방식은 확산 인자와 지연 시간이 동일하지 않 다는 특징을 가진다.

$$
S=\sum_{i=1}^{M} r_{i} r_{i-L}
$$


식(2)는 CDSK 방식의 수신기의 상관기 출력을 수 식으로 나타낸 것이다. CDSK 수신기에서 수신 신호 $\left(r_{i}\right)$ 와 지연된 수신신호 $\left(r_{i-L}\right)$ 의 곱을 확산인자만큼 더하여 Threshold를 거친 후에 Decoding을 통해 정보 신호를 복구한다.

\section{Proposed CDSK Receiver}

기존 CDSK 수신기는 그림 2를 보면 알 수 있듯이 수신 신호와 지연 수신 신호를 곱하는 구조로 구성되 어 있다. 하지만 이 구조는 원하는 신호 외에 다른 요 소들이 더해지기 때문에 BER 성능이 나쁘게 평가되는 것이다.

$$
\begin{aligned}
S= & \sum_{i=1}^{M}\left(x_{i}+b_{i} x_{i-L}+\xi_{i}\right)\left(x_{i-L}+b_{i} x_{i-2 L}+\xi_{i-L}\right) \\
= & b_{i} \sum_{i=1}^{M} x_{i-L}^{2}+\sum_{i=1}^{M} n_{i} \\
n_{i} & =x_{i} x_{i-L}+\xi_{i} x_{i-L}+b_{i} x_{i} x_{i-2 L}+b_{i}^{2} x_{i-L} x_{i-2 L} \\
& +\xi_{i} b_{i} x_{i-2 L}+x_{i} \xi_{i-L}+b_{i} x_{i-L} \xi_{i-L}+\xi_{i} \xi_{i-L}
\end{aligned}
$$

식(3)과 식(4)는 기존 수신기의 상관기 출력을 수식 으로 표현한 것이다. 식(3)을 보면, $\xi_{i}$ 는 잡음 신호를 의미하며, 두 개의 항 중에 첫 번째 항이 원하는 신호 이며 두 번째 항이 잡음처럼 더해지는 신호이다. 식(4) 는 잡음처럼 더해지는 두 번째 항의 요소들을 나타낸 것이다. 식(3)과 식(4)를 보면, 원하는 신호를 제외한 나머지 신호들이 모두 잡음처럼 더해지며 그 요소가 굉장히 많고 시스템 성능에 영향을 끼칠 수 있다는 것 을 알 수 있다. 만약, 식(4)의 항의 수를 줄일 수 있다 는 것은 간섭 신호나 잡음처럼 더해지는 신호를 줄일 수 있다는 것을 의미하며, 이를 통해 시스템 성능에 미 치는 영향을 최소화 시킬 수 있다는 것이다.

그림 3은 BER 성능 향상을 위해 제안하는 수신기를 나타낸 것이다. 기존 수신기는 카오스 신호의 정보 없 이 수신신호와 지연된 수신신호를 곱하여 정보신호를 복원하였지만 제안하는 수신기는 카오스 신호의 정보 를 모두 알고 있어야 한다. 그림 3을 보면, 기존 수신기 와는 다르게 정보신호와 지연 카오스 신호를 곱하여 정보신호를 복원한다.

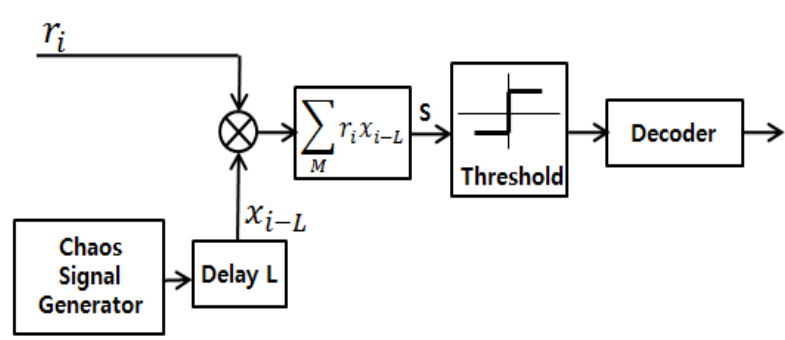

그림 3. 제안하는 CDSK 방식의 수신기.

Fig. 3. Proposed CDSK Receiver.

DCSK와 CDSK 변조 방식의 CDSK 수신기 구조의 상관기 출력은 수신신호와 지연된 수신신호의 합으로 나타난다. 즉, DCSK 방식이던 CDSK 방식이던, 송신 기에서 사용한 확산 인자와 지연 값만 안다면 기존 수 신기 구조로 정보 신호를 복구할 수 있다는 문제점이 존재한다. 하지만 제안하는 수신기를 사용하여 정보 신 호를 복원하기 위해서는 송신기에서 사용한 카오스 신 호의 정보와 지연시간, 확산 인자 값을 모두 알고 있어 야 한다.

$$
\begin{aligned}
S & =\sum_{i=1}^{M}\left(x_{i}+b_{i} x_{i-L}+\xi_{i}\right) x_{i-L} \\
& =b_{i} \sum_{i=1}^{M} x_{i-L}^{2}+\sum_{i=1}^{M} n_{i} \\
n_{i} & =x_{i} x_{i-L}+\xi_{i} x_{i-L}
\end{aligned}
$$

식(5)와 식(6)은 제안하는 CDSK 수신기의 상관기 출력을 수식으로 표현한 것이다. 식(5)를 보면, 식(3)과 마찬가지로 두 개의 항 중에 첫 번째 항이 원하는 신호 이며 두 번째 항이 잡음처럼 더해지는 신호이다. 식(6) 을 보면, 수신된 신호와 카오스 신호를 곱하게 되면 간 섭 신호나 잡음 요인이 기존 수신기보다 굉장히 적어 지는 것을 알 수 있다. 따라서 제안하는 수신기를 사용 하면 이 요인이 적기 때문에 $\mathrm{BER}$ 성능이 향상된다.

제안하는 수신기로 정보 신호를 복구하기 위해서 많 은 조건 값을 알아야하며 수신단에 카오스 신호 발생 기가 추가되어 시스템이 조금 복잡해지는 단점이 존재 한다. 하지만 기존 수신기보다 수신단의 복잡도가 증가 하더라도 자체 간섭 신호를 굉장히 줄일 수 있기 때문 에 $\mathrm{BER}$ 성능이 향상되며 송신단에서 발생시킨 카오스 신호와 똑같은 신호가 발생되어야 정보신호를 복구할 수 있기 때문에 보안성도 훨씬 좋아진다.

따라서 복잡도가 증가하더라도 제안하는 수신기의 구조를 사용함으로써 더 많은 장점을 가질 수 있다. 또 한, 재밍 신호나 간섭 신호가 수신신호에 섞여 들어오 더라도 기존 수신기보다 영향을 받는 요소가 굉장히 
적기 때문에 성능이 덜 나빠진다.

\section{IV. 성능 평가}

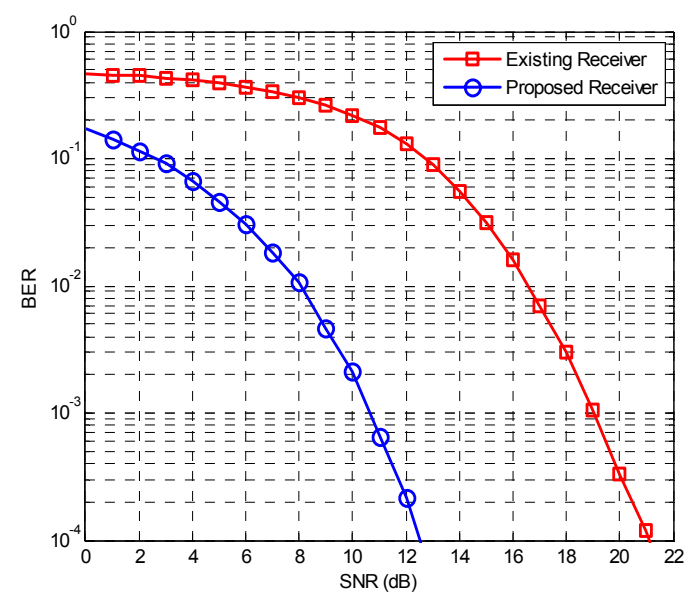

그림 4. 제안하는 $\mathrm{CDSK}$ 수신기의 BER 성능.

Fig. 4. BER Performance of Proposed CDSK Receiver.

제안하는 CDSK 수신기의 성능 평가는 AWGN 환 경에서 실시한다. 성능 평가 시 사용한 카오스 맵은 Logistic Map이며 확산인자는 100으로 설정하였다. 그 림 4는 기존 CDSK 수신기와 제안하는 CDSK 수신기 의 BER 성능을 비교한 것이다. 그림 4 를 보면, 제안하 는 수신기의 $\mathrm{BER}$ 성능이 월등히 좋다는 것을 알 수 있다. 제안하는 수신기의 성능이 좋은 이유는 앞장에서 설명한대로 원하는 신호를 제외한 간섭 신호나 잡음이 굉장히 적기 때문이다. 이런 이유로 제안한 수신기를 사용할 경우에 다른 디지털 시스템의 BER 성능만큼 $\mathrm{BER}$ 성능이 향상된다.

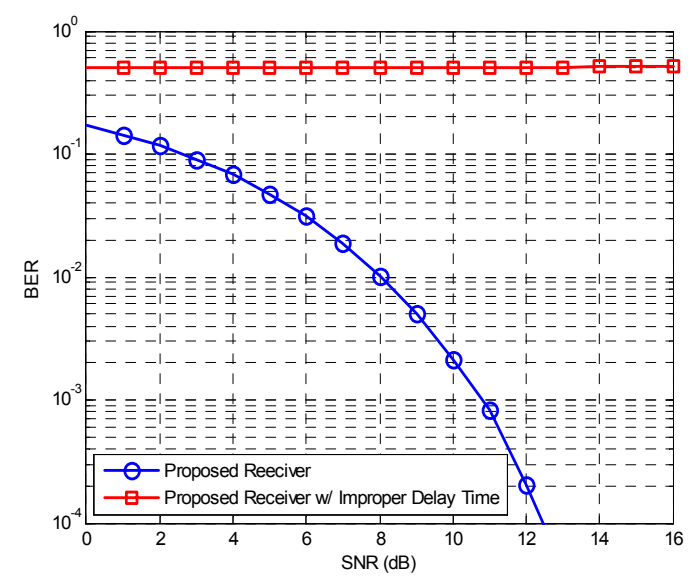

그림 5. 잘못된 지연 시간이 적용된 경우의 $\mathrm{BER}$ 성능.

Fig. 5. BER Performance of proposed receiver that is applied improper delay time.
그림 5 는 송신단에서 사용한 지연 시간이 잘못된 경 우의 BER 성능을 나타난 것이다. 제안하는 수신기를 사용하는 경우, 기존 CDSK 방식과는 다르게 송신단에 서 사용한 카오스 신호 정보와 지연 시간을 정확하게 알고 있어야 한다. 만약, 정확하게 알지 못한다면 그림 5 와 같이 정보 신호를 복구하지 못한다. 따라서 정보 신호를 복구하기 위해서는 더 많은 조건을 정확하게 알아야하므로 그만큼 정보 신호 복구는 어려워지지만 보안성이 좋아진다.

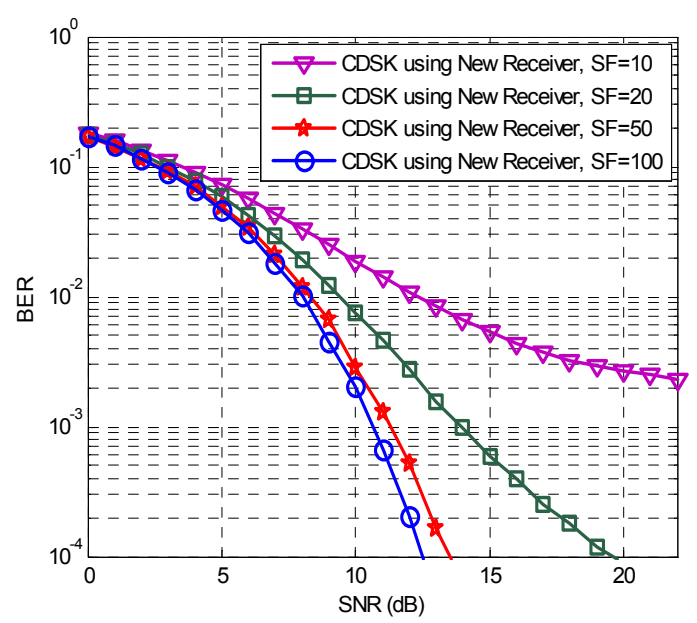

그림 6. 확산 인자에 따른 제안하는 수신기의 BER 성능.

Fig. 6. BER Performance of Proposed Receiver according to Spreading Factors.

그림 6은 제안하는 CDSK 수신기를 사용했을 때, 확산인자에 따른 $\mathrm{BER}$ 성능을 나타낸 것이다. 그림 6 을 보면, 확산인자 값이 커지면 커질수록 $\mathrm{BER}$ 성능은 향상되는 것을 알 수 있다.

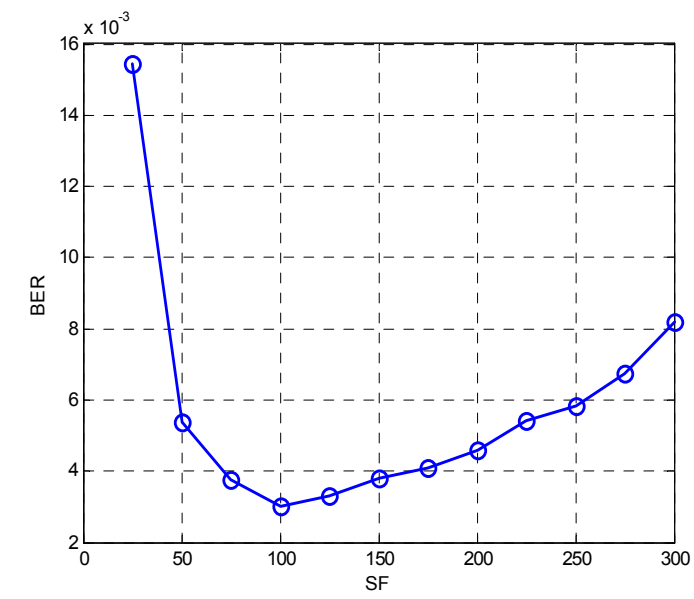

그림 7. 확산인자에 따른 기존 수신기의 BER 성능.

Fig. 7. BER Performance of Existing Receiver according to Spreading Factors. 
그림 7은 확산인자에 따른 기존 CDSK 수신기의 $\mathrm{BER}$ 성능을 나타낸 것이다. 그림 7을 보면, 기존 CDSK 수신기를 사용할 경우, 확산인자가 100 일 때 가장 좋은 $\mathrm{BER}$ 성능을 가지며 확산인자가 커짐에 따 라 $\mathrm{BER}$ 성능이 좋아지다가 100 을 기점으로 나빠지게 된다. 즉, 기존 CDSK 수신기를 사용할 때, Logistic $\mathrm{Map}$ 을 카오스 신호로 사용하고 확산인자 값이 100이 면 가장 좋은 $\mathrm{BER}$ 성능을 가진다는 것을 의미한다. 확 산 인자가 커지면 확산 이득으로 인해 BER 성능이 좋 아지게 된다. 하지만 확산 인자가 너무 커지면 간섭 의 영향을 많이 받게 되어 BER 성능이 나빠지는 것이다. 이런 이유로 인해 기존 CDSK 수신기를 사용했을 때, 확산인자가 커짐에 따라 $\mathrm{BER}$ 성능이 좋아지다가 나빠 지는 것이다.

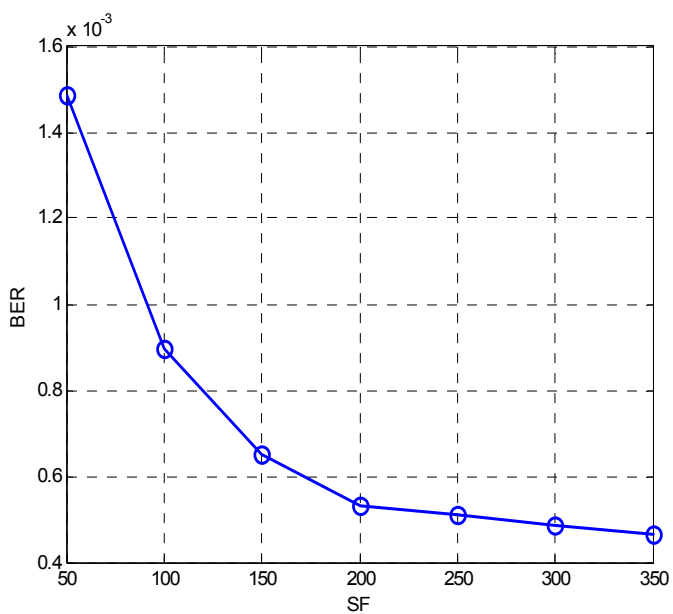

그림 8. 최고의 $\mathrm{BER}$ 성능을 가지는 확산인자에 대한 성능평가.

Fig. 8. Performance Evaluation about Spreading Factors for Best BER performance.

그림 8은 제안하는 수신기를 사용했을 때, 확산인자 에 따른 BER 성능을 나타낸 것이다. 그림 7을 보면, 확산인자가 커짐에 따라 BER 성능이 향상되는 것을 알 수 있다. 그림 7과 그림 8을 비교해보면, 기존 CDSK 수신기를 사용할 때에 확산인자가 100 일 때 가 장 좋은 $\mathrm{BER}$ 성능을 나타내지만 제안하는 수신기는 확산인자가 커지면 커질수록 $\mathrm{BER}$ 성능이 좋아진다.

확산 인자가 너무 커지면 간섭의 영향을 많이 받게 되어 $\mathrm{BER}$ 성능이 나빠지는데, 제안하는 CDSK 수신 기를 사용하면 원하는 신호 이외에 간섭 신호나 잡음 요소가 굉장히 적기 때문에 확산 인자가 계속 커져도 $\mathrm{BER}$ 성능이 개선되는 것이다.

기존 $\mathrm{CDSK}$ 수신기를 사용할 때는 가장 좋은 $\mathrm{BER}$ 성능을 가지게 하는 확산 인자를 선택적으로 사용하였
지만 제안하는 CDSK 수신기를 사용한다면 큰 확산인 자 값을 설정하면 되기 때문에 선택의 폭이 넓어진다.

\section{V. 결 론}

본 논문에서는 $\mathrm{BER}$ 성능 향상을 위해 새로운 CDSK 수신기를 제안한다. 제안한 수신기는 기존 수신 기와는 다르게 카오스 맵 정보를 모두 알고 있어야 정 보신호를 복구할 수 있다. 기존 수신기와 제안한 수신 기의 $\mathrm{BER}$ 성능을 비교해본 결과, 제안한 수신기를 사 용하였을 때 BER 성능이 굉장히 향상되는 것을 알 수 있다. 이는 원하는 신호 외에 더해지는 간섭 신호나 잡 음의 영향이 굉장히 적기 때문이다. 기존 수신기를 사 용하였을 때, 확산인자 값이 100 인 경우에 가장 좋은 $\mathrm{BER}$ 성능을 나타내지만 제안한 수신기를 사용한 경우 에는 확산인자가 커질수록 $\mathrm{BER}$ 성능이 향상된다. 이 로 인해, 기존의 수신기를 사용하는 경우보다 제안한 수신기를 사용할 경우 확산인자의 선택폭이 굉장히 넓 어진다.

\section{References}

[1] G. Kaddoum, D. Roviras, P. Charge, and D. Fournier-Prunaret, "Performance of multi-user chaos-based DS-CDMA system over multipath channel," in Proc. IEEE Int. Symp. Circuits Syst. (ISCAS), pp. 2637-2640, Taipei, Taiwan, May 2009.

[2] C. YiPing, S. Ying, and Z. Dianlun, "Performance of differential chaos-shift-keying digital communication systems over several common channels," in Proc. 2010 2nd Int. Conf. Future Comput. Commun. (ICFCC), vol. 2, pp. 755-759, May 2010.

[3] S. I. Hong and E. Y. Jang, "FPGA implementation of digital transceiver using chaotic signal," Korea Inst. Inform. Technol. Review, vol. 8, no. 8, pp. 9-15, Aug. 2010.

[4] G. Kaddoum, P. Charge, D.Roviras and D. Fournier-Prunaret, "A methodology for bit error rate prediction in chaos-based communication systems," Circuits Syst. Signal Process., vol. 28, no. 6, pp. 925-944, Dec. 2009.

[5] J. Bok and H.-G. Ryu, "Digital chaotic 
communication system based on CDSK modulation," J. Korean Inst. Commun. Inform. Sci. (KICS), vol. 38A, no. 6, pp. 479-485, June 2013.

[6] M. Sushchik, L. S. Tsimring, and A. R. Volkovskii, "Performance analysis of correlation- based communication schemes utilizing chaos," IEEE Trans. Circuits Syst. I, Fundam. Theory Appl., vol. 47, no. 12, pp. 1684-1691, Dec. 2000.

[7] N. F. Rulkov, M. M. Sushchik, L. S. Tsimring, and A. R. Volkovskii, "Digital communication using chaotic-pulse-position modulation," IEEE Trans. Circuits Syst. I, Fundam. Theory Appl., vol. 48, no. 12, pp. 1436-1444, Dec. 2001.

[8] N. F. Rulkov, M. A. Vorontsov and L. Illing "Chaotic free-space laser communication over turbulent channel," Phys. Rev. Lett., vol. 89, no. 27, pp. 277-905, Nov. 2002.
이 준 현 (Jun-Hyun Lee)

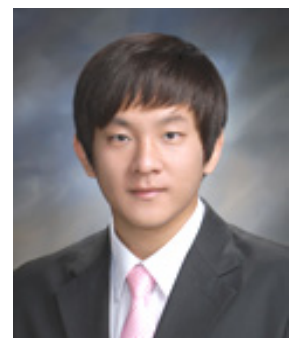

2013년 2월 충북대학교 전자 공학과(공학사)

2013년 3월 현재 충북대학교 전자공학과 석사과정

<관심분야> 보안 통신, 이동 통신 시스템

\section{유 흥 균 (Heung-Gyoon Ryu)}

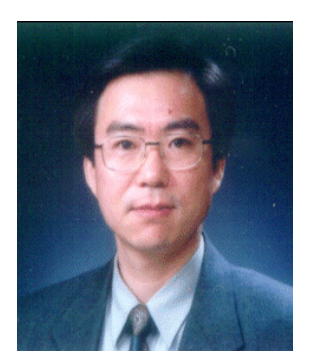

1988년 현재 충북대학교 전자 공학과 교수

2002년 3월 2004년 2월 충북 대학교 컴퓨터정보통신연구 소 소장

1996년 현재 IEEE, IET 논문 심사위원

2002년 한국전자파학회 학술상 수상

2008년 ICWMC 2008 국제학술대회 "Best Paper Award' 수상

2009년 SPACOMM 2009 국제학술대회 "Best Paper Award" 수상

<관심분야> 무선통신시스템, 위성통신, $\mathrm{B} 4 \mathrm{G} / 5 \mathrm{G}$ 이 동통신시스템, 통신회로 설계 및 통신 신호 처리 